\title{
Sustainable development and reconstruction of the architectural ensemble in Kirzhach, depending on the natural processes on its territory
}

\author{
Sergey Chernyshev ${ }^{1, *}$, Aleksey Evgrafov ${ }^{2}$, and Irina Evgrafova ${ }^{1}$ \\ ${ }^{1}$ Moscow State University of Civil Engineering, Yaroslavskoeshosse, 26, 129337, Moscow, Russia \\ ${ }^{2}$ Russian State Agrarian University - Moscow Timiryazev Agricultural Academy, Timiryazevskayast. \\ 49, 127550, Moscow, Russia
}

\begin{abstract}
The architectural ensemble of the convent, which has been developing since the XV century in the city of Kirzhach in the center of the European part of Russia, is under the influence of processes in soils and water bodies on its territory. Ignorance of builders of the past centuries about processes repeatedly led to accidents of constructions. Preserved ancient buildings have deformation marks in bearing structures. They are caused by the slow horizontal movement of soils towards the valley side of the river Kirzhach, which stands from the deformed, but not destroyed by the process cathedral on tens of meters. The process of horizontal movement of soils to the river is stimulated by lateral erosion - stream bank erosion by river. In the result of geo-ecological research, on the plan of the ensemble territory were identified areas, which are to different extents exposed to dangerous for constructions natural processes. The measures on protection of existing constructions of the ensemble from dangerous natural and technology-induced processes are recommended, the design of foundations of new constructions capable to protect the top constructions of buildings from harmful influences of geological environment is submitted.
\end{abstract}

\section{Introduction}

Sustainable development of cities and reconstruction of architectural ensembles are possible in the modern, disturbed by anthropogenic influences natural environment only by improvement of technical and architectural decisions with account of special aspects of natural and technology-induced environment. Successful work in this direction can be done only on the basis of high-quality research of the environment. In the construction complex the research of the environment is performed by the Engineering Survey. The task of the Engineering Survey is to study the structure, properties of the natural environment and processes proceeding in it. This report shows how the structure of the environment and it's

* Corresponding author: 9581148@list.ru 
hidden processes, identified by specialists, orchestrate the plot plan of development and design features of structures.

\section{Materials and methods}

The method of research of the question considered in the report is expert. The authors studied the published works [1-7] and materials on the history of Architectural ensemble and engineering-geological conditions of its territory, supervised exploration works, in which the drill holes and pits were passed to clarify the deformations of the foundations, visited and inspected the monastery, water bodies and the relief of the valley of the river many times in different years. There were no significant changes during 20 years of periodic observations.

\section{Research Object}

The Kirzhach Holy Annunciation Convent - a monument of federal importance of Russia a unique place on Russian soil. It is the "younger brother" of the world-famous Holy Trinity-St. Sergius Lavra, it is the only monastery, besides the Lavra, which was founded and in which for 2 years lived great church and public figure of Rus Reverend Sergius Radonezhsky, one of the main participants of the recreation of the Russian state in the XIV century after the dissolution and devastation of Kievan Rus. The Kirzhach Convent played an outstanding role in the life of the Old Russian state for centuries, as evidenced, in particular, by the letters issued to the convent by Grand Prince Ivan III and the Great Princess SofyaVitovtovna in the XV century. The Annunciation Cathedral, built in the last quarter of the XV century, the Saviour Church of the middle of the XVII century, as well as other buildings [8-10] preserved in its ensemble

The territory of the monument is located in the city of Kirzhach, situated in the center of the European Russia, 90 kilometers northeast of Moscow. The ensemble stands above the river Kirzhach at an altitude of 20 meters above the water level in the river. It occupies a perfectly flat horizontal platform, so flat that the natural flow of atmospheric waters is not provided (Fig. 1).

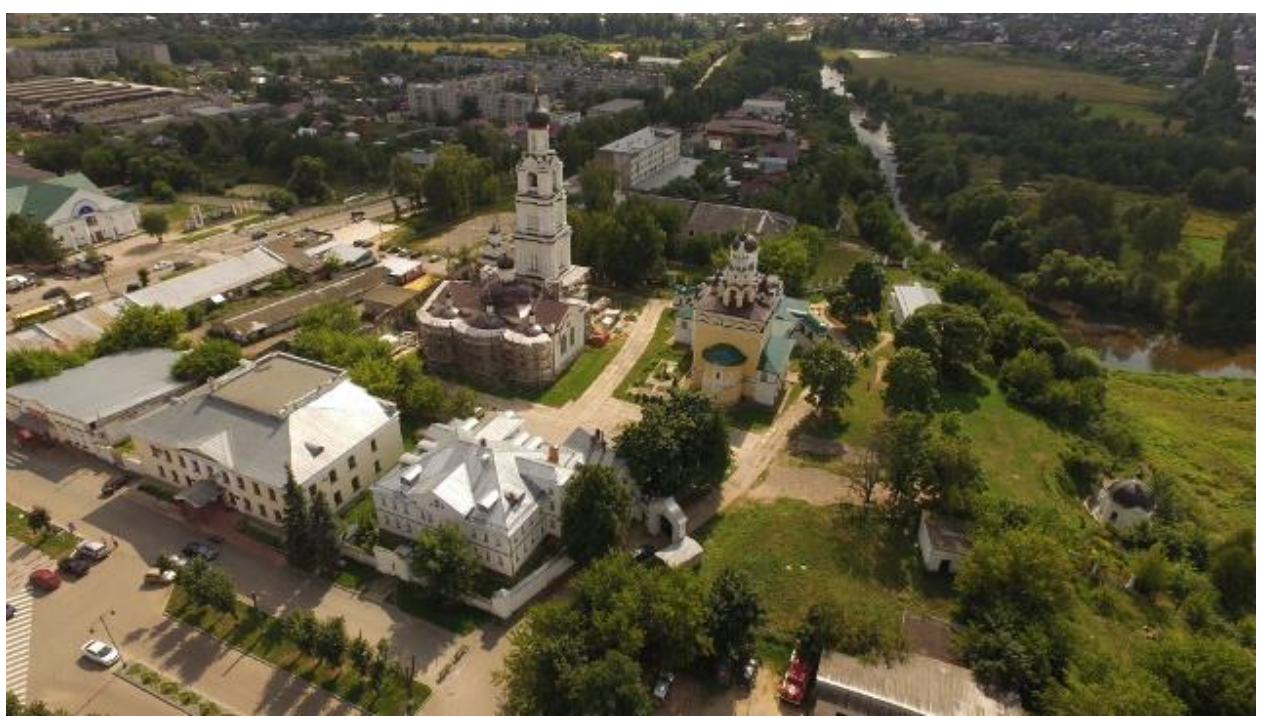

Fig. 1. General view of the territory of the Convent. 
This makes it difficult to exploit the territory, creates conditions for its flooding $[11,12$, 13]. The site rises above the river Kirzhach on $20 \mathrm{~m}$ and is separated from the river by the steep side of the valley. The slope is flat, inclined at an angle of 33 degrees to the horizon. There is a course of the river directly under it and dead stream branch which in the recent past was a course. On the plan the slope is perfectly flat for long distance, which suggests that it is connected with a deep rift in the foundation of Russian slab and expressed in relief as lineament over this rift. Flood plain is flat, steeply-slopping and rises above the course on $4 \mathrm{~m}$.

The territory, on which the convent is situated, is composed by sandy quaternary and chalk deposits through the full height of the slope. The marked 33 degrees of the slope correspond to the angle of rest for sands. The slope is in a state of limit equilibrium [14, 15]. At the level of river line sands is underlain with heavy layer of clay of Jurassic age. There is a 2-metre layer of sandy and clay composition at a depth interval of $8-10 \mathrm{~m}$ from the surface in the sands. On this layer underlies the thin aquifer, nourishing a weak source in the middle part of the slope. There is a chapel above the source, located on a steep slope. The water layer in the aquifer is $0.2-0,3 \mathrm{~m}$. At the level of the river in the cretaceous sands underlies ground-water line, the second from the surface. The surface of the upper line is located at 7-9 m below the surface of the ground, the second aquifer - almost $20 \mathrm{~m}$ below the surface of the ground. Ground water of the aquifers does not affect the use of the territory. The upper aquifer is polluted with surface drainage. Two layers of clay under monastery are fully waterlogged, as over each of them there is a permanent aquifer. It can be stated that the relief and geological and hydrogeological structure of the slope under the territory of the architectural monument can contribute to the formation of landslide deformations. Deformation of soils and structures will be considered below.

Water bodies on the territory immediately adjacent to the convent are represented by a river and a pond. The Kirzhach River valley, rectilinear in plan, runs along the southwest border of the architectural ensemble. 100 years ago, in the recent past, the course of the river was along the fence of the convent and was not seen under the steep riverside scarp of $20 \mathrm{~m}$ height. In the twentieth century it changed its position. Now the river under the convent crosses the valley and approaches the riverside slope perpendicular to the bank. Here it changes direction 90 degrees and leaves the territory of the monument of architecture approaching to a slope over which the convent stands. The source has a width of about $30 \mathrm{~m}$. Flow rate at low water level is $0.3 \mathrm{~m} / \mathrm{sec}$. During seasonal flood the level of the river does not threaten the territory of the ensemble, located on $20 \mathrm{~m}$ above low water level.

The pond is located on the south-east side of the convent at a distance of $50 \mathrm{~m}$ from its fence and $7 \mathrm{~m}$ below the site of the convent. Pond basin is an artificial cut of uneven outlines, approximated in the plan to rectangular form $22 \times 46 \mathrm{~m}$ in size and a depth of 1,5$1,6 \mathrm{~m}$, which is banked up along the entire perimeter. The pond has a natural recharge due to the upper aquifer and atmospheric precipitation falling on its basin. Being closed, it is very vulnerable to pollution and requires civilized exploitation and protection from pollution by urban storm drains, from which it is protected by flood embankment. The pond performs an important ecological function - it drains the territory of the convent on the south-east. On the northwest it is drained by a steep side of the river valley. On the south-west and northeast the territory is also drained by the smooth slopes of the hill crossing the top clay layer. When choosing a place for the convent Reverend SergiusRadonezhsky probably was guided by the fact that the hill was drained on the three sides. In natural conditions favorable hydrogeological conditions of a hill with a flat peak convenient for development and agriculture were expressed by vegetation, probably large pines on a construction site which indicated, that the place was dry, and firs on smooth slopes, where are the discharges of the upper aquifer. Subsequently, the natural drainage system was supplemented by the 
pond, which takes and evaporates ground-water, as the climatic conditions of the territory in question are characterized by the prevalence of evaporation over the annual amount of precipitation.

The ecological culture of exploitation of the territory now requires the preservation and purification of the pond to maintain its drainage function. The territory of Trinity Lavra of St. Sergius is also located on a hill, which is dried on three sides by relatively steep slopes, and on the fourth by dug pond. It is kept clean and is decorated by waterfowl. Reverend SergiusRadonezhsky for his second monastery chose a place in the Virgin Forest similar to the place of the first monastery.

Having considered geomorphological, engineering and geological, hydrological conditions of existence of a monument of architecture - ensemble of Annunciation Convent in Kirzhach, it is possible to proceed to the main aspect of nature management, namely to consider landscape dynamics, which is connected with the interaction of water bodies, soil bodies and forms of relief with connection of vegetation. Natural processes occurring in the territory change it, as the river changed its course 100 years ago, leaving dead stream branch under the convent and changing the course to the opposite side of the valley. Natural processes can threaten ancient structures and the engineering protection should be made to protect them. Planning of the protection of architectural monuments is necessary with account of possible changes of territory under influence of natural processes of river erosion, flooding, landslides.

\section{Results and discussion}

In the natural conditions described above, in the territory of architectural monument of the Annunciation Convent occur the processes of flooding of buildings, erosion of the river bank, landslides on a steep slope near the river and slow plastic movement of soils on the half of the territory adjacent to the riverside scarp of the valley.

The flooding was revealed in the first years of the monastery's architectural monument more than 20 years ago. The territory has not been landscaped yet, too flat horizontal relief did not provide run-off of rain and snow waters. There were drainless concaves on the territory, but they not accumulated puddles as water concentrated in places of concaves, seeped through sand, forming the top $7 \mathrm{~m}$ of a hill, to the upper aquifer. It flowed around old brick and rubble stone foundations, watered it and flooded into the basement equipped for various domestic uses. The struggle with flooding in such geological conditions came down to perfection of vertical planning and installation of open drains.

The erosion (washout) of the river bank occurs where the new source flows in the direction perpendicular to the bank. Water currents strike the shore and change direction by 90 degrees. Thus the kinetic energy of water and floating items on it, ice at flood, logs and others, destroy a malleable ground - the clay which forms the bottom part of a bank slope. The coast becomes steeper and caves, protecting the bottom part of a slope by small volume of slipped soil. But loosened while caving soil - is weak protection from a stream of water. It requires the intervention of builders, the creation of a bank protection structure - banking or other construction. Within the framework of this geo-ecological work we do not set ourselves the task to design the construction, even do not define the type of construction, but only specify where the intervention of builders is required to manage the natural or natural and technology-induced process. During one of our visits to the object we saw how the vegetation came to the aid of the bank being washed out. A large tree with massive crown and roots collapsed from the slope. Water in the law water level could not wash it away, only turned it along the bank. In such way nature built temporary bank protection structure in expectation of intervention of people-defenders of the architectural monument. 
There are no big landslides in the convent and the adjacent territory. The mains soil mass consists of sand which is not of landslide-forming type. Clay layer at a depth of 8-10 $\mathrm{m}$ with layers of filtering soils, pervious, waterlogged is dangerous element of geological section both by composition and condition. A layer of clay, which underlies in the base of the slope at the level of river line is also dangerous from the context of landslide threat evaluation. But in recent decades there have been no landslides on these layers. There are no traces of earlier landslides on the slope to the river, too. This caving slope for more than 600 years of existence of the convent, apparently, was not disturbed by large landslides. However, the potential danger of small landslides in top layer of clay and large landslides in the lower layer of clay still exists. Strictly speaking, it is necessary to check the stability of the steep slope by calculation, for which it is necessary to make the calculation model by the method of engineering surveys under a special program.

Small landslides of the depth of about one meter, on an area of several tens of meters moving on the steep slope being watered in the upper part by the waters of the upper aquifer and being washed out on a small area by the river. In this context, in general, the flat bank of the river has hummocky micro-relief. However, the chapel on the source on the slope has no signs of deformation. In the upper part of the slope small and shallow landslides threaten the lines of engineering communications, which without considering the geo-ecological situation are imprudently laid directly at the edge of the slope. Designing communications, designers went away from closely built up territory to the free of development strip by a slope, but got in a dangerous zone.

The process of deep-earth slow plastic deformations, which in engineering geology are considered to be the stage of preparation of large landslides, is the most interesting from the scientific and practical point of view. It has been recorded by deformations of buildings from XVI century up to modern. Buildings with centuries-old history are not destroyed, but deformed. In this regard, it is interesting to consider the history of construction on the site located at $15-20 \mathrm{~m}$ from the steep slope to the river. Now there is a Brethren's building, residential building built in the late XIX century (Fig. 2).

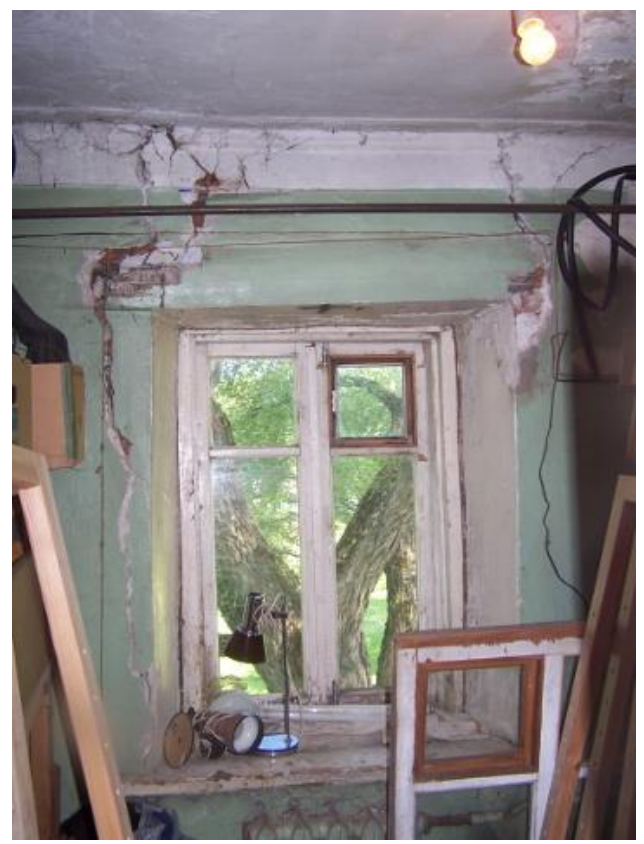

Fig. 2. Deformation of the walls of the Brethren's building (inner view). 
Based upon the old plan, in the year 1875 the building of the City Duma with a different plan of foundations stood on this place. In XVII-XVIII centuries there was another bulk. All of them one after another had become unsafe and were dismantled. The modern building has also become unsafe. Its walls oriented along the slope are inclined. In the walls perpendicular to the slope are through cracks of width up to several centimeters. Everything indicates the stretching of the building in the direction perpendicular to the slope. It stands on absolutely flat ground, but obviously moves horizontally together with bottom soils towards the slope. And the wall close to the slope moves faster. Based upon the cracks, the difference of velocities is not less than $1 \mathrm{~mm} / \mathrm{year}$. The life of the building in such conditions is about 100 years, after which it is dismantled and newly built in the same place on the same strip foundation.

The building of the Church of the Annunciation and the Savior Cathedral are exposed to the same process of wall movement. This cathedral is at 70 meters from the slope. There are cracks parallel to the slope. Their orientation indicates the presence of horizontal velocity of the soil movement to the river. However, the cathedral is not in unsafe condition. There were cracks in total disclosure of a few centimeters found in its foundation by test drilling. Here the difference of velocities of movement of walls on a big time interval from XVI century is about $0.1 \mathrm{~mm} /$ year, 10 times less, than on the site by the slope. There is a long crack from an entrance portal to a chancel screen with a width of about $1 \mathrm{sm}$ in a cement floor of the temple, which was made about 100 years ago. The velocity over the last 100 years is estimated by the same size by it, as during the whole period of the cathedral existence.

In the Church of All Saints built in 1865-66 years, located at a distance of 130-150 m from the slope there is no cracks. Here, despite the large distance between the walls of the building, the difference of velocities of their movement to the river cannot be recorded. It can be stated that in the territory of the historical architectural ensemble there is a slow horizontal movement of soils towards the valley of the river. The velocity of this movement decreases gradually and at a distance of more than 100 meters cannot be fixed.

It can be assumed that the cathedral, which existed on the territory of the monastery in the name of Reverend Sergius Radonezh, dismantled in Soviet times also had significant cracks of the described character. It stood much closer to the slope than the Savior Cathedral and therefore could be close to unsafe condition. Was it dismantled during the anti-religious struggle of the state with orthodoxy, because it needed repair, while other cathedrals could be used without repair for economic needs? The fact of the deformation of buildings in the slope zone was investigated earlier at other sites in Moscow and on the Anzer island of Solovetsky archipelago.

\section{Conclusions}

Carried out geo-ecological analysis of the quality of the territory of the Annunciation Convent in Kirzhach shows that its place was successfully chosen in the XIV century by Reverend Sergius - the founder of the monastery. It is flat and dry with sandy soils on the top, which are not exposed to dangerous process of frost heave and allow shallow laying of foundations. The presence of an aquifer at a small depth of 8-10 $\mathrm{m}$, then clean and suitable for water supply of a small number of brethren. The presence of the "road" in the form of Kirzhach, suitable for communication in summer and winter, allowed to connect it with the rare inhabited places of the principality of Muscovy.

The development of the site was not prevented by significant dangerous natural processes for a number of centuries. Karst holes are impossible here, despite the steep and watered slope there are no large landslides, there is no serious flooding, as the hill is dried naturally on three sides, and on the fourth there is a drainage facility - a pond. 
The builders of the last centuries did not notice the process of slow plastic movement of soils in the slope part towards the slope. This process destroyed and deformed the buildings but still is not taken into account by the builders. At those velocities of horizontal movement of soils which are fixed here by deformations of buildings, it is the raft foundations that should be used in new constructions, but not strip and isolated foundations. The old buildings should be tied with a reinforced concrete belt at the foundation level. According to the theory of engineering geology, the slow horizontal movement of the soils towards the slope reflects the preparation of a large landslide. Therefore it is necessary to carry out special researches with calculation of a stability margin of a slope on such territories, as a site of Annunciation Monastery.

\section{References}

1. E.M. Sergeyev, Engineering Geology of the USSR in eight volumes (Moscow University Publishing house, Moscow, 1978)

2. S.N. Chernyshev, I.M. Evgrafova, M.A. Neklyudov, News of Higher Educational Institutions Construction 8, 107-114 (2014)

3. S.I. Macij, E.V. Bezuglova, Geo-ecology, engineering geology, hydrogeology, geocryology 6, 537-546 (2007)

4. G.I. Bondarenko, A.G. Alekseev, Mining industry and mining sciences at the turn of the century the collection of reports of the international scientific and practical Conference, 146-155 (2002)

5. T.M. Ponomareva, Influence of soil creep on deformation of structures. In the collection: Mechanics and management processes Materials of the All-Russian scientific-practical conference (2015)

6. M.G. Demchishin, I.I. Koltunov, Geologichnij Magazine 3, 23-29 (2005)

7. V.A. Babello, S.V. Smolich, T.Y. Valceva, S.M. Kaligin, Engineering Geology 1, 3741 (2015)

8. O.V. Zarochinceva, Materials of the International scientific and practical Conference. Collection of articles (2014)

9. N.V. Yudina, Monuments of Kirzhach as motivation of development of architectural and landscape environment of the city, Proc. of the Int. Sci. and practical conference, teaching staff, young scientists and students (2017)

10. O.V. Zarochinceva, Ensemble of the Kirzhach Holy Annunciation Convent and its composite role in the city. Proc. of the Int. Sci. conference, teaching staff, young scientists and students (Moscow Architectural Institute (State Academy), 2014)

11. A.A. Loskutova, Engineering surveys for construction on the landslide hazard slope. In the collection: Geology in the developing world materials of the VIII scientific and practical conference "Perm State National Research University" (2015)

12. E.V. Antoshkina, Geography and global energy 1, 106-111 (2013)

13. A.B. Ponomarev, S.V. Kaloshina, S.I. Starceva, M.A. Bezgodov, Construction in urban areas Perm (2012)

14. A.I. Konyuchenko, Magistra Vitae: electronic journal of historical sciences and archeology 1, 100-111 (2017)

15. S.V. Sol'skiy, N.F. Krivonogova, Y.Y. Savel'yeva, L.I. Svitel'skaja, D.V. Petrov, E.V. Bulganin, News of the All-Russian Research Institute of Hydrotechnics named B.E. Vedeneeva 256, 81-88 (2009) 